\title{
The biomedical informatics short course at Woods Hole/Georgia: Training to support institutional change
}

\author{
James J. Cimino* \\ Informatics Institute, University of Alabama at Birmingham, Alabama, USA
}

\begin{abstract}
The US National Library of Medicine's Biomedical Informatics Short Course ran from 1992 to 2017, most of that time at the Marine Biological Laboratory in Woods Hole, Massachusetts. Its intention was to provide physicians, medical librarians and others engaged in health care with a basic understanding of the major topics in informatics so that they could return to their home institutions as "change agents". Over the years, the course provided week-long, intense, morning-to-night experiences for some 1,350 students, consisting of lectures and hands-on project development, taught by many luminaries in the field, not the least of which was Donald A.B. Lindberg M.D., who spoke on topics ranging from bioinformatics to national policy.
\end{abstract}

Keywords: US National Library of Medicine, Donald A.B. Lindberg M.D., biomedical informatics training, Marine Biological Laboratory

In memory of Catherine N. Norton M.S.I.S., 1941-2014.

Director, Marine Biological Laboratories/Woods Hole Oceanographic Institute Library

\section{Introduction}

Donald A.B. Lindberg M.D. firmly believed that the way to promote the adoption of informatics tools, resources and methods in the healthcare community was through outreach programs. Those programs exposed "change agents" from participating institutions to available informatics resources and applications and demonstrated what they could do. In 1990, Don learned of an informatics workshop that, despite being (in his opinion) of low quality, provided an inspiration for a new outreach mechanism.

This chapter describes the results of that inspiration - a short course on medical informatics, sponsored by the National Library Medicine. I will trace history of the development of the course, take a look at how the instructional topics changed over time, and try to give the reader a sense of why the course was such an exceptional experience for students and faculty who participated in it. While I cannot provide an in-depth analysis of the course's impact on the field of biomedical informatics, I reference some published work on the subject.

\footnotetext{
* Corresponding author: James J. Cimino, M.D., University of Alabama at Birmingham, 1900 University Boulevard, Birmingham, Alabama 35294, USA. E-mail: ciminoj@uab.edu.
} 